\title{
Mujer de 41 años con lesiones cutáneas
}

\author{
41 Year old woman with skin lesions
}

\author{
Liroa Romero $\mathrm{MF}^{1}$, García Trincado B' ${ }^{1}$, Loureiro Martínez $\mathrm{M}^{2}$, Rabuñal Rey $\mathrm{R}^{3}$ \\ ${ }^{1}$ Servicio de Medicina Interna, Hospital Universitario Lucus Augusti. ${ }^{2}$ Servicio de Dermatología, Hospital Comarcal de Monforte de Lemos \\ ${ }^{3}$ Unidad de Enfermedades Infecciosas, Hospital Universitario Lucus Augusti
}

\section{RESUMEN}

La lepra o enfermedad de Hansen, es una entidad nosológica infecciosa producida por Mycobacterium leprae. No se conoce exactamente su mecanismo de transmisión. Es más frecuente en hombres y aparece habitualmente entre la segunda y tercera década de la vida. El diagnóstico de lepra es clínico, sin embargo la presencia de los bacilos en frotis y biopsias cutáneas y la detección de su ADN permiten su confirmación. El tratamiento es largo y la curación se consigue tras varios años sin enfermedad. Presentamos un caso de lepra autóctono atendido en nuestro centro. Mujer de 41 años de edad, española, agricultora que consulta por presentar lesiones cutáneas redondeadas, con centro deprimido, eritematodescamativas en el borde y acompañadas de unas lesiones cutáneas nodulares en miembros inferiores. Se decidió biopsiar las lesiones nodulares que confirmaron el diagnóstico de lepra. Se inició tratamiento y las lesiones cutáneas evolucionaron favorablemente hasta su resolución. Actualmente existen dos casos de lepra activos y tres en vigilancia tras el tratamiento. En Galicia es poco habitual, y casi siempre está en relación con población inmigrante.

\section{INTRODUCCIÓN}

La lepra o enfermedad de Hansen, es una entidad nosológica infecciosa producida por Mycobacterium leprae. No se conoce exactamente su mecanismo de transmisión, sin embargo para llegar a contagiarse de la misma es necesario mantener un contacto muy íntimo y prolongado. El periodo de latencia de la enfermedad es variable y suele durar entre 3 y 10 años. Cuando se manifiesta la enfermedad afecta principalmente a la piel, a los nervios periféricos y a las vías aéreas superiores¹. Es más frecuente en hombres y aparece habitualmente entre la segunda y tercera década de la vida. El diagnóstico de lepra es clínico (lesiones cutáneas hipopigmentadas o rojizas, afectación de nervios periféricos con pérdida de sensibilidad fundamentalmente), sin embargo la presencia de los bacilos en frotis y biopsias cutáneas y la detección de su ADN en la reacción en cadena de la polimerasa (PCR) permiten su confirmación ${ }^{2}$.

El tratamiento recomendado por la OMS es prolongado; 6 meses para casos paucibacilares y 12 meses los multibacilares. La curación se determina tras dos años libre de enfermedad en los paucibacilares y 5 años en los multibacilares ${ }^{3}$.

Presentamos un caso de lepra autóctono atendido en nuestro centro.

\section{CASO CLÍNICO}

Mujer de 41 años de edad, española, agricultora, bebedora de una unidad de bebida estándar diaria. Se intervino en 2003 de un quiste sacro. Estaba en tratamiento con Anticonceptivos orales.

\begin{abstract}
Leprosy or Hansen's disease is an infectious nosological entity produced by Mycobacterium leprae. Its transmission mechanism is not known exactly. It is more common in men and usually appears between the second and third decade of life. The diagnosis of leprosy is clinical, however the presence of bacilli in smears and skin biopsies and the detection of their DNA allow their confirmation. The treatment is long and the cure is achieved after several years without disease. We present a case of autochthonous leprosy attended in our center. A 41-year-old Spanish woman, a farmer who consulted due to rounded skin lesions, with a depressed center, erythematodescampathetic on the edge and accompanied by nodular skin lesions on the lower limbs. It was decided to biopsy the nodular lesions that confirmed the diagnosis of leprosy. Treatment was started and the skin lesions evolved favorably until their resolution. Currently there are two cases of active leprosy and three in surveillance after treatment. In Galicia it is unusual, and it is almost always related to the immigrant population.
\end{abstract}

Palabras claves: Lepra, lesiones cutáneas, autóctono, Galicia. Keywords: Leprosy, skin lesions, autochthonous, Galicia

Consultó en Dermatología en julio de 2016 por presentar lesiones cutáneas de 15 días de evolución en la mitad superior del cuerpo, de características redondeadas, con centro deprimido, eritematodescamativas en el borde y acompañadas de unas lesiones cutáneas nodulares en miembros inferiores. En la analítica se observó una velocidad de sedimentación globular (VSG) de 68 y ligera leucocitosis con neutrofilia. La biopsia demostró un patrón anatomopatológico compatible con dermatosis neutrofílica. Se diagnosticó de eritema nodoso en probable relación con anticonceptivos orales y se indicó tratamiento con corticoides orales durante 25 días en pauta descendente.

En la revisión al mes persistió la clínica; se realizó una segunda biopsia donde se objetivó un infiltrado inflamatorio linfocitario de predominio perivascular e intersticial, en la dermis papilar con extensión a la dermis reticular y algunos neutrófilos aislados. La epidermis mostraba espongiosis y degeneración hidrópica de la capa basal focal y leve como únicas alteraciones significativas. No había vasculitis ni extravasación de hematíes. Se mantuvo el diagnóstico previo y se pautó otro ciclo de esteroides durante 20 días.

Dos meses después consultó de nuevo por empeoramiento de las lesiones (figura 1 y 2). Se reinició tratamiento con prednisona y se añadió colchicina. Una nueva analítica objetivó un discreto aumento de los reactantes de fase aguda. Se decidió biopsiar nuevamente una de las lesiones nodulares de la cara interna de la rodilla con el siguiente resultado: epidermis conservada; en la dermis se observó un importante infiltrado inflamatorio histiocitario rodeando los vasos, nervios y también perianexial. La tinción de Ziel-Neelsen mostró bacilos ácido-alcohol-resistentes. La tinción de Wade-Fite-Faraco mostró asimismo estructuras compatibles con micobacterias. Los hallazgos descritos fueron compatibles histológicamente con lepra. Se remitió a nuestro centro para completar estudio. La exploración 
Figura 1a, 1b y 1c: lesiones nodulares eritematosas en piernas.
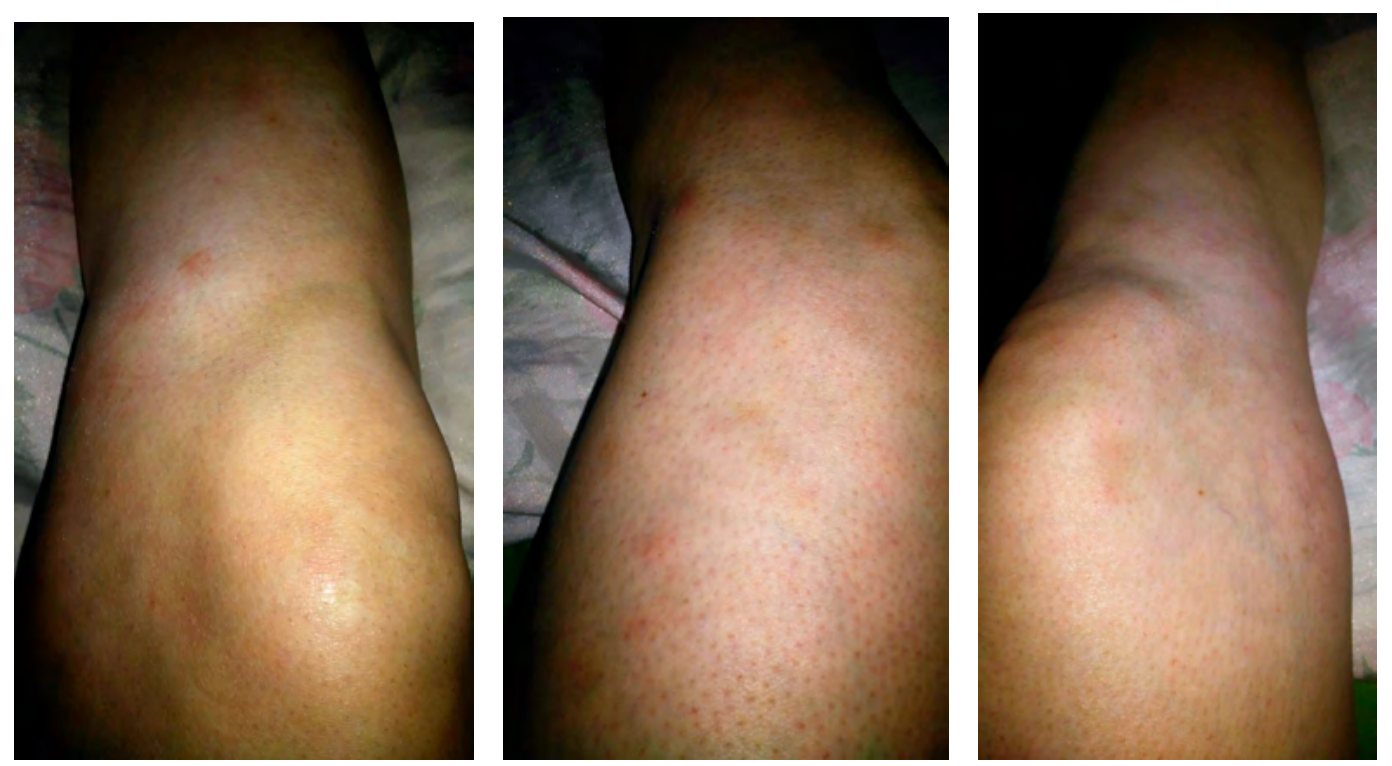

Figura 2a y 2b: lesiones eritematodescamativas de dorso de las manos.
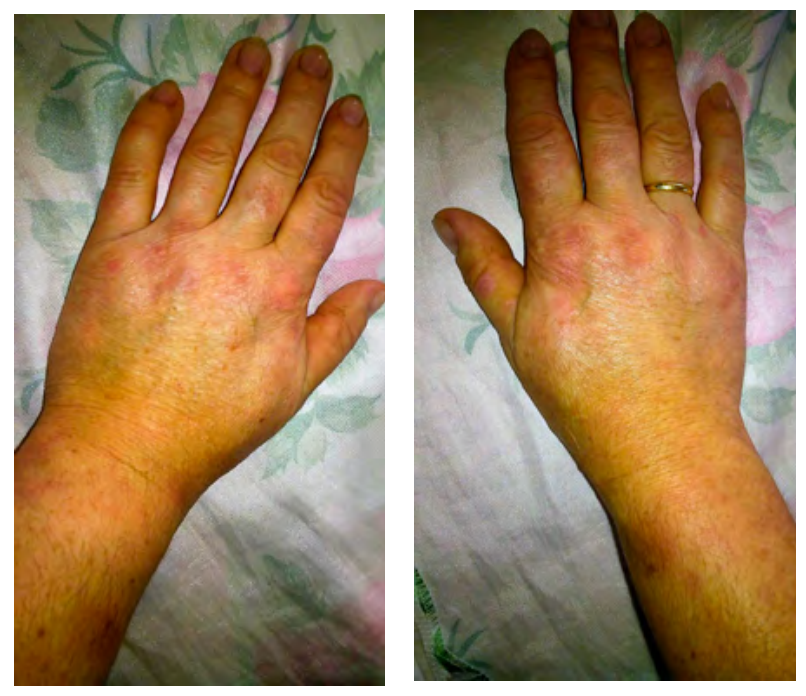

Figura 3a y 3b. Blister de tratamiento.
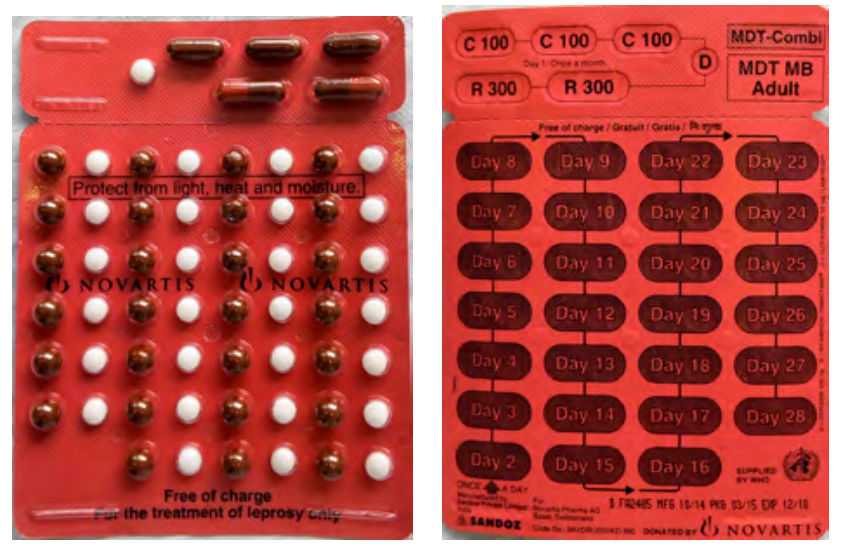

neurológica fue normal y el electromiograma no objetivaba lesiones nerviosas a ningún nivel. Se realizó serología de Virus de hepatitis B y C, VIH, Lúes y Borrelia, las cuales fueron negativas. Las baciloscopias y PCR para micobacterias en orina fueron negativas. Se decidió practicar una tercera biopsia de una lesión nodular de las extremidades inferiores confirmándose los hallazgos de la biopsia previa, aunque la baciloscopia, cultivo y PCR para micobacterias (tuberculosis y lepra) fueron negativas. Se tomó un frotis nasal donde se observaron escasos bacilos ácido-alcohol-resistentes, y otro de linfa en lóbulo de oreja que fue negativo.

Con el diagnóstico de lepra probablemente lepromatosa se instauró tratamiento según pauta OMS de doce ciclos (un año) con: Rifampicina 600 miligramos una vez al mes y clofazimina 300 miligramos una vez al mes, continuándose posteriormente con clofazimina 50 miligramos diarios y dapsona 100 miligramos diarios ${ }^{4}$. Antes del inicio del tratamiento se solicitó los niveles de glucosa6-fosfato-deshidrogenasa que fueron normales.

Durante el tratamiento las lesiones cutáneas evolucionaron favorablemente hasta su resolución.

Se realizó exploración dermatológica a los contactos (hijos y esposo) sin encontrarse lesiones relevantes.

\section{DISCUSIÓN}

La lepra es una enfermedad infecciosa que cursa con una evolución crónica causada por Mycobacterium Leprae'. Afecta fundamentalmente a la piel y el sistema nervioso. El desarrollo de la enfermedad, de sus manifestaciones clínicas y de la evolución dependen fundamentalmente de la respuesta inmune del individuo, condicionada por sus características genéticas además de otros factores como los socio-económicos, geográficos, sexo y edad². El diagnóstico de la enfermedad se basa en las manifestaciones clínicas, confirmándose definitivamente con los resultados positivos de las baciloscopias, la histopatología y PCR para micobacterias. En nuestro caso, la clínica, y las pruebas complementarias (baciloscopia y biopsia) confirman el diagnóstico. La nega- 
tividad de la PCR podría explicarse por la escasa cantidad de ADN en las muestras analizadas, habitualmente paucibacilares y la falta de estandarización de esta prueba en nuestro medio.

El tratamiento es prolongado y complejo, por lo que para mejorar la adherencia al tratamiento se han desarrollado una serie de blísteres en los que se especifica el fármaco y la dosis a tomar cada día (figura 3). Una vez completado el tratamiento, los pacientes deben realizar una consulta de revisión anual con estudio de baciloscopia de lesiones cutáneas y PCR de linfa durante 5 años en casos de lepra multibacilar y durante 2 años en caso de lepra paucibacilar ${ }^{5-6}$.

En España, en 2016 se identificaron 11 casos nuevos de lepra, en 2017, 8 casos de los cuales 1 consta España como país de contacto7. Concretamente en Galicia se notificaron 23 casos de lepra entre el 1993-2012. Desde entonces hasta el 2017 se han notificado 5 casos; 4 en La Coruña, 1 en Orense. Tres de los cinco eran mujeres y todos tenían entre 25-55 años de edad. Se conoce que todos eran importados originariamente de Brasil. Sólo un caso, en 2013, fue de nueva aparición y el resto fueron recidivas. Actualmente dos casos siguen activos y tres en vigilancia tras el tratamiento.

En Galicia el diagnostico de lepra es poco habitual, y casi siempre está en relación con población inmigrante. De ahí el interés de nuestro caso, en una paciente autóctona y sin foco de contagio conocido.

\section{BIBLIOGRAFÍA}

1. Smith CS, Aerts A, Saunderson P, Kawuma J, Kita E, Virmond M. Multidrug therapy for leprosy: a game changer on the path to elimination. Lancet Infect Dis. 2017; 17:e293-e297.

2. Steinmann P1, Reed SG2, Mirza F3, Hollingsworth TD4, Richardus JH5. Innovative tools and approaches to end the transmission of Mycobacterium leprae. Lancet Infect Dis. 2017: 17:e298-e305.

3. Venres epidemiolóxico. Folla quincenal de información epidemiológica de Galicia. Vol. 7, 14. 13 Julio 2018. Conselleria de sanidades. Disponible en: https:// www.sergas.es/Saude-publica/Documents/5510/Nenres\%20Epidemioloxico_ vol7_n\%C2\%BA14_14072018.pdf

4. Suárez Moreno 0. Baciloscopia de la lepra. Instituto de Medicina Tropical "Pedro Kouri". Ciudad Habana, Cuba. 2017. Disponible en: http://files.sld.cu/ipk/ files/2010/02/baciloscopia.pdf

5. Protocolo de vigilancia y alerta de lepra. Red nacional de vigilancia epidemiológica. Marzo 2012. Disponible en: https://www.juntadeandalucia.es/export/drupaljda/ salud_5af95879cce70_p_LEPRA_2012.pdf

6. Manual de procedimiento. Registro Estatal de lepra. España (revisado en 1996) Centro Nacional de Epidemiología (Instituto de Salud Carlos III), Ministerio de Sanidad y Consumo. Ministerio de Asuntos Sociales. Disponible en: http://www. isciii.es/isciii/es/contenidos/fd-servicios-cientifico-tecnicos/fd-vigilancias-alertas/ fd-procedimientos/protocolos_renave-ciber.pdf

7. Boletín epidemiológico semanal. España (2017) Centro nacional de epidemiología (Instituto de Salud Carlos III), Ministerio de Sanidad y Consumo. Ministerio de Asuntos sociales. Disponible en: http://www.isciii.es/ISCIII/es/contenidos/fd-servicios-cientifico-tecnicos/fd-vigilancias-alertas/fd-boletines/boletin-epidemiologicosemanal-red.shtml 